\title{
Risk factors associated with overweight and obesity among reproductive aged (15-49) years females in urban areas of Rajbiraj Municipality, Saptari
}

\begin{abstract}
Overweight and obesity has threatened the modern world not only in developed countries but equally in developing countries like Nepal. The study therefore aimed to assess the risk factors associated with overweight and obesity among reproductive aged women residing in Rajbiraj Municipality. A cross-sectional descriptive study was done on reproductive aged females (15-49 years) using a structured questionnaire. Weight, height, waist circumference and hip circumference were measured to determine indicators related to overweight and obesity. The anthropometric measurements were then analysed using WHO and IDF criteria. Microsoft excel 2007 and SPSS version 20 were used to analyze data. Chi square test was used to analyze the factors associated with BMI, WC and WHR cut-offs. The results showed a high prevalence of overweight and obesity in reproductive aged females residing in Rajbiraj. Hence, concerned agencies should launch appropriate programs to combat the factors
\end{abstract}

Keywords: obesity, reproductive age, dietary intake, risk factors, socio-economic status, overweight
Volume 10 Issue 3 - 2020

\author{
Chandani shah,' Pallavi Vyas Jaisani, ${ }^{2}$ Madan \\ Pandey, ${ }^{3}$ Om Prakash Sah,' Mukundha ${ }^{4}$ \\ 'Department of Dietetics and Nutrition, Birat Medical College \\ and Teaching Hospital, Nepal \\ ${ }^{2}$ Tribhuwan University, Nepal \\ ${ }^{3}$ Rapti Academy of Health Science, Nepal \\ ${ }^{4}$ Plastic surgeon, Birat Medical College and Teaching Hospital, \\ Nepal
}

Correspondence: Chandani Shah, BSc. Nutrition and Dietetics, Central Campus of Technology, Rajbiraj, Provience 2, Nepal, Emailshahchandani32@gmail.com

Received: June 14, 2020 | Published: June 30, 2020
Abbreviations: STEPS, step wise approach to surveillance; WHO, world health organization; IDF, international diabetic federation; SPSS, statistical package for social science; BMI, body mass index ; WC, waist circumference; WHR, waist to hip ratio; $\mathrm{NCD}$, non-communicable disease; NHRC, Nepal health and research council

\section{Introduction}

Overweight and obesity are defined as abnormal or excessive fat accumulation that may impair health. ${ }^{1}$ Obesity is a metabolic disease that has reached epidemic proportions. The World Health Organization (WHO) has declared obesity as the largest global chronic health problem in adults which is increasingly turning into a more serious problem than malnutrition. In 2014, more than 1.9 billion adults (18 years and older) were overweight of these over 600 million were obese, 42 million children under the age of 5 were overweight or obese in $2013 .^{2}$ It has been further projected that $60 \%$ of the world's population, i.e. 3.3 billion people, could be overweight ( 2.2 billion) or obese ( 1.1 billion) by 2030 if recent trends continue. ${ }^{3}$ Different studies have showed an association between obesity and mortality factors such as diabetes, hypertension, $\mathrm{CHD}$, and some cancers. The increase in overweight and obesity is concerning for future generations as there is a positive association between obesity and chronic health conditions such as Type II diabetes, hypertension, atherosclerosis, cardiovascular disease (CVD), joint pain, depression, etc. ${ }^{4}$ In addition to the physical consequences of excess body fat, overweight and obese adolescents and children often develop psychological issues such as low selfesteem, nervousness, and sadness. ${ }^{5}$ Obesity, in particular abdominal adiposity, is associated with increased risk of cardiovascular disease. ${ }^{6}$ Overweight and obesity is amazingly increasing in Nepal among reproductive aged females. In Nepal trends of overweight and obesity among women is found to be increasing with $7.1 \%$ overweight and $2.4 \%$ obesity in 2007 to $17.3 \%$ overweight and $4.8 \%$ obesity in 2013 (NHRC, 2014). Similarly, mean waist to hip ratio among women was found to be 0.55 in 2007 study while 2013 STEPs survey shows its figure to 0.9 . The current prevalence of overweight and obesity is more among female as compared to male in Nepal..$^{7}$ Obesity is a physiological risk factor for non- communicable diseases (NCDs). The objective of the study was to assess prevalence of overweight and obesity in reproductive aged females in Rajbiraj and to find out socio-economic status, dietary intake, physical activity level, behavioural factors and health factors. The study results may be useful in highlighting the problem of overweight and obesity and the main contributing factors among women in Rajbiraj.

\section{Material and methods}

\section{Study area}

The study was conducted at Rajbiraj, a mid-sized municipality located in the south-eastern region of the Province No.2 of Nepal. Rajbiraj is the district headquarters of Saptari as well as the eighth largest city of the Province No. 2. The city is systematically designed and has been the first township in Nepal to receive urban planning. ${ }^{8 f}$

\section{Study population}

Target population of the study was reproductive aged women of 15 to 49 years of age residing in Rajbiraj Municipality, Saptari.

\section{Selection criteria}

\section{Inclusion criteria}

Women residing in Rajbiraj of age between 15 to 49 years of age were included in the study.

\section{Exclusion criteria}

a. Females who were below 15 years and above age 49 .

b. Females who were seriously ill, mentally unfit, pregnant and lactating women. 
c. Females residing in hospitals, prisons, nursing homes.

d. Females who were not available at household during the time of study.

e. Females who were residing temporarily in Rajbiraj.

\section{Research design and instruments}

\section{Research design}

A cross-sectional study of reproductive aged females (15-49years) residing in Rajbiraj was done where prevalence of overweight and obesity and their associated risk factors were assessed. It consisted of:

I. Anthropometric measurements

II. Survey with the help of semi structured questionnaire

\section{Research instrument}

Instruments used for the research work were:

a. Stadiometer: A well calibrated stadiometer, measuring up to 200 $\mathrm{cm}$ with least count of $0.1 \mathrm{~cm}$, to assess the height of participants.

b. Digital weighing balance: A digital weighing balance measuring up to $180 \mathrm{~kg}$ with least count of $0.1 \mathrm{~kg}$.

c. Questionnaire: Well designed and pretested set of questionnaire to collect information on demographic variables, socio-economic condition, dietary practices and related habits, environmental conditions of the targeted participants.

\section{Sampling technique}

For sampling, probability proportional to size (PPS) method was used. Among 16 wards, 4 wards were chosen for sample selection by simple random sampling technique. Sample size in each ward was separately calculated. Only one female from each households were chosen for study.

\section{Sample size}

The sample size was determined by using a single proportional formula assuming the combined prevalence rate of overweight and obesity to be $22 \%,{ }^{8} 95 \%$ confidence interval (CI), $7 \%$ margin of error (d) and 10\% non-response rate is added to the total calculated sample size. The WHO STEPS NCD survey conducted in Nepal in 2013 was taken as the reference proportion.

$\mathrm{N}=$ sample size, $\mathrm{p}=$ estimated proportion of an attribute present in the population, $\mathrm{z}=$ confidence interval at $95 \%$ (standard value of $\mathrm{z}$ is 1.96)

$$
\begin{aligned}
& \text { Sample size }(\mathrm{N})=\mathrm{Z}^{2} \times \mathrm{p}(1-\mathrm{p}) / \mathrm{d}^{2} \\
& \text { Now, } \mathrm{N}=1.96^{2} \times 0.22 \times(1-0.22) /(0.07) 2^{2} \\
& \text { Sample size for known population, } \\
& \mathrm{N} \div(1+(\mathrm{N}-1) \div \text { total population }) \\
& =132 \div(1+(132-1) \div 22431) \\
& =131
\end{aligned}
$$$$
\text { Now, } \mathrm{N}=1.96^{2} \times 0.22 \times(1-0.22) /(0.07)^{2}=132
$$

Considering non-response rate as $10 \%$, the adjusted sample size is calculated to be 144 .

\section{Study variables \\ Dependent variables}

The dependent variables of the study were body mass index (BMI), waist circumference and waist to hip ratio.

\section{Independent variables}

Independent variables included in the study were as follows:

I. Socio-economic and demographic variables: Age, caste, religion, marital status, income, occupation, education, parity, family size.

II. Physical activity: Physical activity was categorized as low, moderate and high according to the score of each individual calculated following the short IPAQ questionnaire.

III. Dietary intake: With the help of information obtained from dietary assessment nutrients like fat, energy, calorie, carbohydrates were calculated and classified according to WHO recommendations

IV. Health related characteristics: Menstrual disorders, use of contraceptives.

V. Behavioural characteristics: Watching TV while eating, sleep, stress, eating food outside, smoking, alcohol intake.

\section{Pre-testing}

The prepared sets of questionnaire and anthropometric instruments were pre-tested among few women. Pre-testing was conducted in order to maintain accuracy and clarity of questionnaire, to check the consistency in interpretation of questions by respondents and to identify ambiguous item. After pre - testing all the ambiguous, misleading and wrongly interpreted questions was omitted and questionnaire was revised in accordance with the findings of pretesting and suggestions.

\section{Validity and reliability}

Validity of instrument was ascertained by comparing the data provided by our weighing balance with standard weights. Likewise validity of stadiometre was ascertained by comparing the measurement from our stadiometre and UNICEF stadiometre. Measuring tape was calibrated against standard stadiometre. The instruments were checked and reset daily to validate the data. For 24 hours recall, different foods were standardized in measuring cups for data collection. The questionnaire was validated by reviewing different literature designed to assess the dietary habit, physical activity and other behavioural factors of reproductive aged women. The questionnaire was also pretested prior to data collection to ascertain content validity.

\section{Data collection techniques}

Data collection was spread over two phases, namely, initial contact with the participant, completing the semi structured questionnaire and in second phase anthropometric measurements were taken. The socio-demographic and economic variables part involved asking the respondents about their age, marital status and parity, income, education and occupation. Information on other variables and data on anthropometric measurements were obtained by following methods.

Physical activity: Physical activity part was used to collect data on type, frequency, duration and intensity of physical activity during work, transportation and leisure time in a typical week. Data on 
physical activity were collected using the short form of "International Physical Activity Questionnaire (IPAQ)". The purpose of the questionnaires is to provide common instruments that can be used to obtain internationally comparable data on health-related physical activity. ${ }^{9}$

Dietary intake: Data was collected using a food frequency questionnaire and the 24- hour recall method. The food frequency questionnaire was used to obtain information on the type of foods consumed by the respondents in the preceding days and the frequency of consumption of those foods. Various foods from different food groups were read out to the respondent, who in return was required to state the number of times she had consumed the food in the preceding days. The 24-hour recall involved asking the participants to report on all the foods and drinks consumed in the previous 24 hours (the previous day), in direct chronological order from the first foods in the morning to the last foods before going to bed. Probing was allowed to obtain information on forgotten foods. Utensils like glasses, spoons, cups and plates were used for estimating the amount of foods and beverages actually consumed by the respondents. The gram equivalents of those foods were calculated which was used to calculate amounts of nutrients consumed.

Anthropometric measurements: Anthropometric measurements were conducted by measuring height with the help of stadiometre, weight with the help of weighing balance and waist and hip with the help of non-stretchable measuring tape.

a. Waist circumference: It was measured at the mid-point between the lower border of the rib cage and the iliac crest. Waist circumference was measured using a non-stretchable tape halfway between the lower border of ribs and the iliac crest on a horizontal plane, while ensuring that the tape was level around the body and parallel to the floor. The tape was tightened around the body without depressing the skin. ${ }^{10}$ Two measurements to the nearest $0.1 \mathrm{~cm}$ were taken and the mean recorded.

b. Hip circumference: It was measured around the highest point of hip. Hip circumference was measured using a non-stretchable tape. ${ }^{10}$ Two measurements to the nearest $0.1 \mathrm{~cm}$ were taken and the mean was recorded.

c. Weight: Weight was measured to the nearest 100 grams $(0.1 \mathrm{~kg})$ using a weighing scale with the capacity of $180 \mathrm{~kg}$, after calibrating it to zero, and after removal of shoes and excess clothing. Both weight and height were taken twice. In order to ensure quality data, the weighing scale was calibrated before measuring of weight every day and after every five measurements during the data collection time. ${ }^{10}$

d. Height: Height was measured using stadiometre with the capacity of $197 \mathrm{~cm}$ and to the nearest $0.1 \mathrm{~cm}$. The subject was told to stand (without shoes) on a horizontal platform with his heels together and with the Frankfurter plain horizontal. The subject draws himself to full height without raising the shoulders with arms and hands relaxed and with the feet flat on the ground. ${ }^{10}$

e. BMI: It was measured by respondents weight in kilograms divided by the square of height in meters.

\section{Data analysis}

The questionnaire were checked and rechecked at the end of each day. After the data are manually edited and coded, they are entered into a database immediately. Microsoft Excel 2007 and SPSS version 20 were used to analyze data. Descriptive analysis was used to describe percentage and distribution of respondents by socio demographic variables, physical activity, dietary patterns, medical characteristics and behavioral characteristics. Likewise, qualitative data were transcribed and coded by assigning labels to various categories. Chisquare test parameters were used to establish the relationships between the variables and indicators of overweight and obesity in women.

\section{Logistic and ethical considerations}

Permission to conduct study was received from Nutrition and dietetics department, Central Campus of Technology. Ethical approval was obtained from Nepal Health and Research Council (NHRC). An informed written and verbal consent was obtained from all the participants. The objectives of the research were explained in local language. Privacy and confidentiality of collected data was ensured.

\section{Results}

More than half of the respondents, 54.7\% (79) performed low physical activity and $42.7 \%$ (61) of respondents performed Moderate physical activity. Only $2.6 \%$ (4) respondents were engaged in high physical activity. As, females are only engaged in household work like cleaning, washing, cooking etc., they tend to have low physical activity. Only few females were living in rural part of Rajbiraj performed heavy physical activity in form of agricultural work (Table 1). According to Asian BMI cut- off $68.7 \%$ (99) of females were overweight or obese while remaining were not. The study found that $42 \%$ (60) of female were overweight and $26.7 \%$ (39) were obese. The mean waist circumference was found to be $86.3 \mathrm{~cm}$ which is far more than the mean WC of NCD STEPs survey $2013(76.7 \mathrm{~cm})$ conducted in Nepal. ${ }^{11}$ According to waist circumference measurement 59\% (84) were found to be abdominally obese while $41 \%$ (60) were not . Family monthly income, eating away from home, Wheat intake, Fast food intake, dairy products intake, fat intake and meat intake are found to be significantly associated with BMI categorized according to WHO cut off as shown in Table 2. Results should be clear and concise and also separate from the Discussion part (Table 3). Each Tables and Figures must be found below their respective paragraphs from the Results part (Table 4).

Table I Distribution of physical activity $(n=144)$

\begin{tabular}{lll}
\hline Physical activity & Frequency & Percentage \\
\hline High & 4 & 2.6 \\
Moderate & 61 & 42.7 \\
Low & 79 & 54.7 \\
\hline
\end{tabular}

\section{Discussion}

According to Asian BMI cut- off $68.7 \%$ (99) of females were overweight or obese while remaining were not. The study found that $42 \%$ (60) of female were overweight and $26.7 \%$ (39) were obese. This prevalence is much greater than the prevalence found in the study done in female living in Ramkot VDC of Kathmandu district where $4.5 \%$ were overweight and only $1.8 \%$ were obese. ${ }^{12}$ This could be because the calorie and fat intake of women residing in Rajbiraj is high. Likewise the prevalence is much higher than the prevalence among urban women residing in Chennai of age 20-49 years where $7.9 \%$ were found to be overweight and $19.8 \%$ were found to be 
obese. ${ }^{13}$ According to waist circumference measurement 59\% (84) were found to be abdominally obese while $41 \%$ (60) were not. The result could be compared to the study done in women visiting TUTH revealed that $82.2 \%$ of women were abdominally obese in terms of waist circumference. ${ }^{14}$ It could be because women visiting TUTH may have any chronic diseases which are the result of being abdominally obese. So, they have comparatively high waist circumference as compared to general reproductive aged female of Rajbiraj. The Figure 1 below shows the prevalence of abdominal obesity in females. Whereas regular intake of dairy products was found to have a significant association with waist circumference measurement. The multivariate analyses s0howed a trend toward increases in weight with high dairy calcium intakes in normal-weight French women (Figure 2). ${ }^{15}$

Table 2 Factors associated with BMI among reproductive aged females residing in Rajbiraj Municipality

\begin{tabular}{|c|c|c|c|c|c|}
\hline Factor & & Overweight/obese & Percentage & Chi square & P-value \\
\hline \multirow[t]{2}{*}{ Monthly income } & $<30000$ & 12 & $15 \%$ & 56.39 & 0.000 \\
\hline & $>=30000$ & 68 & $85 \%$ & & \\
\hline \multirow[t]{4}{*}{ Wheat intake } & Regular & 29 & $35.8 \%$ & 18.37 & 0.031 \\
\hline & Frequent & 39 & $48.1 \%$ & & \\
\hline & Rare & 8 & $9.8 \%$ & & \\
\hline & Never & 5 & $6.1 \%$ & & \\
\hline \multirow[t]{4}{*}{ Fast food intake } & Regular & 0 & $0 \%$ & 28.443 & 0.001 \\
\hline & Frequent & 10 & $12.3 \%$ & & \\
\hline & Rare & 45 & $55.5 \%$ & & \\
\hline & Never & 26 & $32 \%$ & & \\
\hline \multirow[t]{4}{*}{ Dairy products intake } & Regular & 55 & $67.9 \%$ & 17.163 & 0.046 \\
\hline & Frequent & 22 & $27.16 \%$ & & \\
\hline & Rare & 0 & $0 \%$ & & \\
\hline & Never & 4 & $4.9 \%$ & & \\
\hline \multirow[t]{3}{*}{ Fat intake } & Adequate & 72 & $92.5 \%$ & 54.31 & 0 \\
\hline & Inadequate & 9 & $11.1 \%$ & & \\
\hline & High & 0 & $0 \%$ & & \\
\hline \multirow[t]{4}{*}{ Meat intake } & Regular & 1 & 1.23 & 14.84 & 0.095 \\
\hline & Frequent & 26 & $32 \%$ & & \\
\hline & Rare & 39 & $48.14 \%$ & & \\
\hline & Never & 15 & $18.51 \%$ & & \\
\hline
\end{tabular}

Whereas regular intake of dairy products was found to have a significant association with waist circumference measurement as shown in Table 3.

Table 3 Factors associated with abdominal obesity among reproductive aged females residing in Rajbiraj Municipality

\begin{tabular}{llllll}
\hline Factors & & Abdominal obese & Percentage & Chi square & P-value \\
\hline Dairy product & Regular & 55 & $63.20 \%$ & 8.53 & 0.036 \\
& Frequent & 26 & $29.80 \%$ & & \\
& Rare & 2 & $2.20 \%$ & & \\
& Never & 4 & $4.59 \%$ & & \\
\end{tabular}

The study found that working adults who experience job-loss (i.e., become unemployed) gain more weight than those who either stay employed or enter retirement.

Table 4 Factors associated with abdominal obesity among reproductive aged females residing in Rajbiraj Municipality

\begin{tabular}{llllll}
\hline Factors & & Abdominal obese & Percentage & Chi square & P-value \\
\hline Occupation & Employed & 15 & $16.30 \%$ & 4.17 & 0.041 \\
& Unemployed & 77 & $83.60 \%$ & & \\
& &
\end{tabular}

Factors associated with BMI among reproductive aged females residing in Rajbiraj Municipality. 


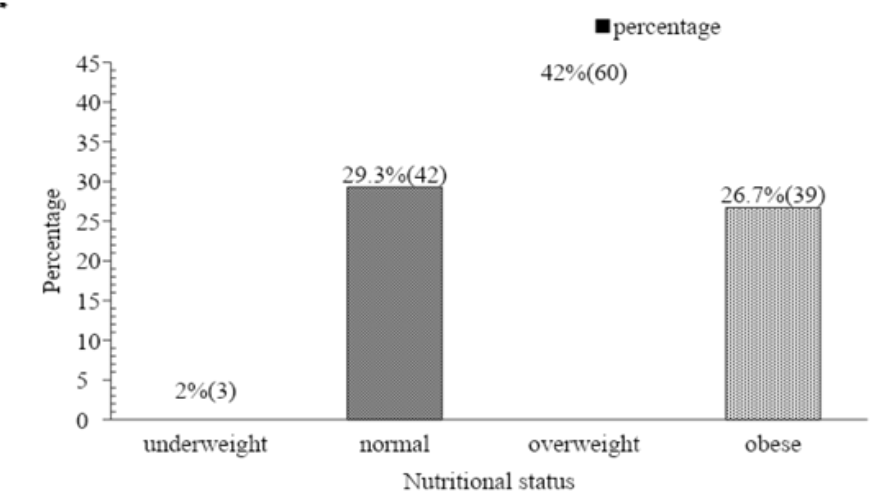

Figure I Prevalence of overweight and obesity in reproductive aged female residing in Rajbiraj Municipality (International cut-off).

$\bullet$

abdominal obese Normal

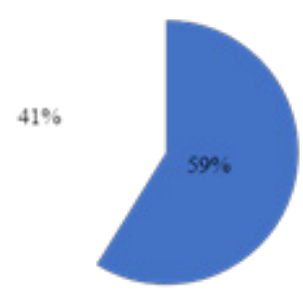

Figure 2 Prevalence of abdominal obesity.

\section{Conclusion}

The study focuses on the factors associated with overweight and obesity in reproductive aged females of Rajbiraj Municipality Saptari. More than half $54 \%$ of women were overweight or obese. It is estimated that for every $1 \mathrm{~kg}$ increase in weight, the prevalence of diabetes rises by $9 \% .{ }^{16}$ The result based on WHR and WC $62 \%$ and $59 \%$ were overweight and obese respectively. The increase in overweight and obesity is a positive association between obesity and chronic health conditions such as Type II diabetes, hypertension, atherosclerosis, cardiovascular disease (CVD), joint pain, depression, etc. The factors associated with overweight and obesity were monthly income $(\mathrm{P}=0.000)$, wheat consumed $(\mathrm{P}=0.031)$, fast food $(\mathrm{P}=0.001)$, dairy products $(\mathrm{P}=0.046)$, fat intake $(\mathrm{P}=0.000)$. Fast food $(\mathrm{P}=0.007)$ and dairy products $(\mathrm{P}=0.036)$ were found to have significant association with waist circumference. Occupation $(\mathrm{P}=0.041)$, were associated with WHR cut-offs. Thus, there was high prevalence of overweight and obesity in reproductive aged female of Rajbiraj Municipality. So, taking in concern with every associated factors, problem of overweight and obesity must be taken as a disease and given a major importance to reduce it.

\section{Acknowledgments}

The authors are grateful to Campus Chief Prof. Dr. Dhan Bahadur Karki, the staffs of Central Campus of Technology and Mr. Dambar Bahadur Khadka, Chairperson, Department of Nutrition and Dietetics, Central Campus of Technology for providing me with all the necessary facilities and support for the research activity. The authors are sindebted to sampled women of Rajbiraj municipality because of their enormous help and passion in providing information and support to my team during data collection activities.

\section{Conflicts of interest}

Authors declare there is no conflicts of interest.

\section{Funding}

None.

\section{References}

1. WHO. Appropriate body-mass index for Asian populations and its implications for policy and intervention strategies. The Lancet. 2004a;363:157-163.

2. WHO. Obesity and Overweight. Fact Sheet no. 311. Geneva: WHO; 2013.

3. Kelly T, Yang W, Chen CS, et al. Global burden of obesity in 2005 and projections to 2030. International journal of obesity. 2008;32(9):1431.

4. Levy C. The Prevalence of Overweight and Obesity Among Adolescents with Chronic Health Conditions. 2017.

5. Ebbeling CB, Pawlak DB, Ludwig DS. Childhood obesity: publichealth crisis, common sense cure. The lancet. 2002;360(9331):473482.

6. Despres J. Intra-abdominal obesity: an untreated risk factor for Type 2 diabetes and cardiovascular disease. Journal of endocrinological investigation. 2006;29(3):77.

7. NHRC. Non-Communicable Diseases Risk Factors: STEPS Survey Nepal 2013 [Report]. Nepal Health Research Council. Kathmandu, Nepal; 2014.

8. MOHP, New ERA, ICF. Nepal Demographic and Health Survey 2016 [Report]. Kathmandu, Nepal; 2017.

9. IPAQ. Addressing overreporting on the International Physical Activity Questionnaire (IPAQ) telephone survey with a population sample. Public health nutrition. 2003;6(3):299-305.

10. CDC. NHANES, Anthropometric procedures manual [Report]. 2007.

11. MOHP. Non communicable diseases risk factors: STEPS survey Nepal 2013. 2013;38-39.

12. Sidik SM, Rampal L. The prevalence and factors associated with obesity among adult women in Selangor, Malaysia. Asia Pacific family medicine. 2009;8(1):2.

13. Anuradha R, Ravivarman G, Jain T. The prevalence of overweight and obesity among women in an urban slum of Chennai. J Clin Diagn Res. 2011;5(5):957-960.

14. Shapkota A, Sapkota A, Acharya K, et al. Study of metabolic syndrome in postmenopausal women. Annals of clinical chemistry and laboratory medicine. 2015.

15. Vergnaud AC, Péneau S, Chat-Yung S, et al. Dairy consumption and 6-y changes in body weight and waist circumference in middleaged French adults. The American journal of clinical nutrition. 2008;88(5):1248-1255.

16. El-Hazmi MA, Warsy AS. A comparative study of prevalence of overweight and obesity in children in different provinces of Saudi Arabia. Journal of Tropical Pediatrics. 2002;48(3):172-177. 